\author{
Zohreh MOGHADDAS, PhD (Corresponding author) \\ E-mail: Zmoghaddas@qiau.ac.ir \\ Department of Mathematics and Statistics \\ Qazvin Islamic Azad University, Qazvin, Iran. \\ Mohsen VAEZ-GHASEMI, PhD \\ E-mail: Mohsen.vaez@iaurasht.ac.ir \\ Department of Mathematics \\ Rasht Islamic Azad University, Rasht, Iran \\ Farhad HOSSEINZADEH LOTFI, PhD \\ E-mail: Farhad@hosseinzadeh.ir \\ Department of Mathematics \\ Science and Research Islamic Azad University, Tehran, Iran.
}

\title{
A NOVEL DEA APPROACH FOR EVALUATING SUSTAINABLE SUPPLY CHAINS WITH UNDESIRABLE FACTORS
}

\begin{abstract}
In every production process, decreasing inputs consumption and increasing outputs production are of desired goals. There exist undesirable outputs in every production process which are by-products of the desirable outputs. Thus, the productions of desirable and undesirable outputs are dependent to each other. This means, productions of undesirable outputs are inevitable. In data envelopment analysis (DEA) literature, many papers considered undesirable outputs in analysis but possible dependencies between production of desirable and undesirable outputs have not been addressed. The aim of this paper is to consider the possible dependency between desirable and undesirable outputs. Then, a DEA model for evaluating a sustainable supply chain as well as each stage in the chains is presented. Some theorems are also provided to describe the model. A case study in a sustainable supply chain is also presented and the results are analysed.
\end{abstract}

Keywords: Data envelopment analysis; Sustainable supply chain management; undesirable outputs.

JEL Classification: G51 - 016 - C45 - N20

\section{Introduction}

Supply chain management (SCM) harmonizes different stages of a supply chain, including supplier, manufacturer, distributer, and retailer. The final goal of a supply chain is to provide goods and services to customers, which lead to the customer satisfaction. Nowadays, in different industries, the sustainability factors play an influential role in success of SCM (Izadikhah and Farzipoor Saen, in press). The sustainability has three aspects, including social, environmental, and economic factors (Kalantary et al., 2019). To manage material, information, and capital flows, the SSCM deals with organizations from three aspects in which environmental is a crucial factor due to dealing with undesirables, (Vaez et al, 
2021). The academic community, governments, businesses, international firms, and non-profit agencies increasingly address the importance of sustainable SCM (SSCM). The social factors focus on human rights, education, and training. The environmental factors include commitment to environmental laws and decreasing utilization of water and energy. The economic factors emphasize on the preservation of economic capitals.

One important issue is having commitment to sustainability principles which cause decision-makers to evaluate the sustainability of suppliers. Therefore, multi criteria decision making (MCDM) frameworks are chosen practically in order to evaluate sustainable suppliers. The sustainability criteria play important role in the productivity of systems. In recent years, managers and decision makers have not only focused on improving the internal processes, but also consider the sustainability factors in supply chains (Rajesh, 2020). Data envelopment analysis (DEA) is a technique that help managers to assess the supply chains. DEA is a mathematical programming technique for the performance evaluation of a set of decision-making units (DMUs). In most of the supply chains, alongside the desirable outputs, undesirable outputs might be produced as well. The undesirable outputs have a bad effect on the sustainability of supply chains. By ignoring the undesirable outputs, measuring the sustainability of supply chains becomes impossible and may lead to unreliable results. Therefore, to assess different supply chains, there exist many factors that should be directly taken into account in order to evaluate the chain as well as its stages, (Borgheipour et al. 2017).

Dealing with undesirable outputs as bad or unwanted products which has adversely affected environments, is one of the main concerns of researchers. Generally speaking, in the DEA literature, there are several ways to deal with the undesirable outputs. In some of the approaches the undesirable outputs are ignored, (Alemdar and Oren, 2006). In some others, the undesirable outputs are manipulated, considered as inputs or transformed, in a way that they can be utilized in standard DEA models (e.g., Tyteca, 1997; Iqbal and Seiford, 1990; Golany and Roll, 1989; Seiford and Zhu, 2002; Kuosmanen and Kortelainen, 2005). In other approaches, the undesirable outputs are incorporated into the DEA mathematics modelling which have more specific focus on impacts of undesirable outputs into the analysis. Hailu and Veeman (2001) provided a modified DEA model which directly dealt with the undesirable outputs. Färe and Grosskpf (2003) claimed that the adapted axiom by Hailu and Veeman (2001) contradict the standard principles of production theory. Kuosmanen (2005) presented a DEA model based on weak disposability axiom and used decreasing non-proportional factors. In his paper, he provided an innovative idea for dealing with undesirable factors while taking DEA axioms into account. Zhou et al. (2006) presented an extended version of the slack based measure (SBM) model which considered undesirable output's decrease as well as desirable output's increase. He proved that the technology introduced by Kuosmanen (2005) is a convex technology that shows joint weak disposability of the desirable and undesirable outputs. D'Inverno et al. (2017) in their paper presented new model while considering several factors such as undesirable outputs, 
A Novel DEA Approach for Evaluating Sustainable Supply Chains with Undesirable Factors

integrated analytic hierarchy process (AHP), and non-radial directional distance function. Huang and Chung (2017) considered a directional technology distance function such that, desirable factors are expanded and undesirable outputs are contracted, simultaneously. Khoshroo et al. (2018) presented a non-radial DEA model for dealing with undesirable outputs. Song et al. (2018) developed a DEA model where minimum undesirable outputs and maximum desirable outputs are considered according to current inputs. Liu et al. (2019) provided a model based on slacks for assessing the eco-efficiency while undesirable factors existed. Shirazi and Mohammadi (2020) presented a robust DEA model for efficiency assessment of airlines in presence of undesirables. They considered DEA as a mathematical modelling technique and considered undesirable outputs.

According to the presented papers for dealing with undesirable outputs for performance assessment of DMUs in DEA literature, it can be noted that each of the provided papers tried to shed more light on dealing with undesirable factors. But clearly these exist some drawbacks. Ignoring the undesirable outputs from the data set and not considering them into the analysis may yield biased results, Alemdar and Oren, 2006. Transforming the data or considering undesirable outputs as inputs for explaining the impact of undesirable outputs may not be matched completely with the standard production theory, cause negative data, and may not correctly introducing the input disposability of inputs, Golany and Roll, 1989; Scheel 2001, Seiford and Zhu, 2002. The model provided by Färe and Grosskpf (2003) was nonlinear. Kuosmanen (2005) made some modification in definitions and introduced an improved model which is also nonlinear. Moreover, Kuosmanen provided a linear counterpart of the models presented in Kuosmanen (2005) and also discussed about the model provided by Färe and Grosskpf (2003).

Undesirable outputs adversely affect the environment; thus, they are damaging factors for supply chains. In this paper, the dependency in production of undesirable and desirable outputs is being discussed and formulated for performance evaluation of supply chains. This means any changes in production of desirable outputs will affect the production of undesirable outputs and vice versa. It should be noted that most of the times, undesirable outputs are by-products of desirable outputs. This concept has direct influence on the performance of the supply chain and its stages as well. This is an interesting and useful topic but not yet has been discussed and formulated in DEA technique. Also, some theorems and a case study are provided to demonstrate how the presented model works.

The current article proceeds as follows: In the next section, the preliminaries of DEA models and undesirable outputs are briefly reviewed. Section 3 provides the new method for dealing with undesirable factors in DEA and supply chains. In Section 4, an application is presented for demonstrating the presented model and method. Finally, a few conclusions are drawn based on preceding discussion. 


\section{Preliminaries and basic DEA models}

Let $D M U_{o}$ denotes a unit from a total of $n$ units whose relative efficiency is being evaluated. Define $x_{o} \in R m_{+}$and $y_{o} \in R s_{+}$as inputs and outputs of $D M U_{o}$. The constant returns to scale form of the two-stage enveloping problem which was first introduced by Charnes et al. (1978), is as follows:

$$
\begin{array}{lll}
\min & \theta-\varepsilon\left(\sum_{i=1}^{m} s_{i}^{-}+\sum_{r=1}^{s} s_{i}^{+}\right) & \\
\text {s.t. } & \sum_{j=1}^{n} \lambda_{j} x_{i j}+s_{i}^{+}=\theta x_{i o}, & i=1, \ldots, m, \\
& \sum_{j=1}^{n} \lambda_{j} y_{r j}-s_{r}^{+}=y_{r o}, & \\
\lambda_{j} \geq 0, & \\
& s_{i}^{-} \geq 0, s_{r}^{+} \geq 0, & \\
\end{array}
$$

In the first phase the radial reduction of inputs is considered. Moreover, in the second phase the summation of input slacks and output surpluses are maximized.

In the production systems there are usually disadvantages of a secondary product generated alongside a good output. For instance, let us consider the electricity generated from a combustion utility, which is a desirable output. $\mathrm{CO}_{2}$, which is an undesirable, detrimental and secondary product is also generated alongside. Undesirable outputs have destructive consequences on environments and the health of humans. Environmental factors such as desirable and undesirable outputs are crucial topics for decision makers and practitioners. Thus, in most of the applications both types of outputs exist and many DEA researchers gauge their effects on the performance of systems and activities.

Fare and Grosscopf (2003) are one of the firsts to introduce the ideas of null-joint outputs and the weak disposability of outputs. Suppose there are $n$ DMUs to be evaluated. Let $(x, y, v)$ be the vector consisting of $m$ inputs, $s$ desirable and $l$ undesirable outputs. The desirable output vector ' $y$ ' is Null-Joint with the undesirable outputs ' $v$ ' if $(y, v) \in P(x)$, and $v=0$ then $y=0$.

Consider $P(x)$ to be the output set. This means, if some good (desirable) outputs are produced, then it is inevitable consequently that some bad (undesirable) outputs are also produced. In other words, considering null jointness, it also can be concluded that if an output vector $(y, v)$ is feasible and no bad outputs are 
A Novel DEA Approach for Evaluating Sustainable Supply Chains with Undesirable Factors

produced, thus only nil good output can be produced. In terms of definition of disposability, Fare and Grosscopf (2003) provided two alternative assumptions, Weak disposability and Strong (Free) disposability of output, concerning output disposability. In definition of Weak disposability of output, in the case that $(y, v) \in P(x)$ and $0 \leq \theta \leq 1$ then $(\theta y, \theta v) \in P(x)$. This definition is based upon the very first definition of weak disposability in the nonparametric activity analysis models that is provided by Shephard (1974). Considering a production technology that generates both desirable and undesirable products (where disposed of the undesirable output is not without consequences) then weak disposability of outputs declares that by holding inputs $x$ constant the desirable outputs must be decreased in the case that undesirable outputs are decreased likewise. In definition of Strong (Free) disposability of output, in the space that $(\bar{y}, \bar{v}) \in P(x)$ and $(y, v) \leq(\bar{y}, \bar{v})$ then $(y, v) \in P(x)$. In accordance to this definition any output, which is inappropriate for a technology, is allowed to be of disposed with consequence. In regards of the above-mentioned definitions, only Strong (Free) disposability can imply Weak disposability but not the converse, Fare and Grosscopf (2003).

\section{A DEA model undesirable outputs in sustainable supply chains}

Data envelopment analysis is a mathematical programming technique for performance assessment of decision-making units and now is widely utilized in different industrial fields. Supply chains (SC), or network structural systems, play significant role in production processes and activities. Supply chain management (SCM) matches different stages of a supply chain, including supplier, manufacturer, distributer, and retailer. Need to be noted that, sustainability plays a fundamental role in success of SCM. Dealing with undesirable, bad, unwanted, or waste, products is one of the concerns of managers and decision makers is Sustainable Supply chains (SSC). An important issue is that undesirable outputs adversely affect the environments and desired to be increased in productions. Need to be noted that undesirable outputs are mostly by-products of desirable outputs. This means, production of undesirable outputs is inevitable. The main idea in this research is to consider this fact that the productions of desirable and undesirable outputs are dependent to each other. More production of desirable outputs will cause more production of undesirable products. This can be a crucial issue in a sustainable supply chain. Since, environmental factors definitely suffer from production of waste and bad products. In this case, increasing the desirable outputs is a decision that should be made with care in order not to destroy environmental factors.

Let $(x, y, v)$ be the vector of input, desirable, and undesirable outputs, respectively. It is usual in manufacturing and production systems that to some extent by performing quality managements and considering managerial disposability (Pouralizadeh et al. 2020) undesirable outputs can be decreased. 
In this occasion, for further reductions in undesirable outputs, desirable outputs should also be decreased. Note that for increasing the desirable output, it is inevitable that the production of undesirable output is also increased. Model (2) is formulated for analysing the whole chain.

$$
\begin{aligned}
& \max \quad \alpha+\varepsilon\left(\sum_{i=1}^{m} s_{i}^{-}+\sum_{r=1}^{1} s_{r}^{+}+\sum_{r_{1}=1}^{s_{1}} \bar{s}_{r}^{+}+\sum_{p=1}^{1}\left(n_{p o}-t_{p o}\right)+\sum_{f=1}^{h} q_{f}^{+}+\sum_{f=1}^{h} q_{f}^{-}\right) \\
& \text {s.t. } \sum_{j=1}^{n} \lambda_{j}^{1} x_{i j}+s_{i}^{-}=x_{i o}-\alpha d_{i}^{x}, \quad i=1, \ldots, m,(a) \\
& \sum_{j=1}^{n} \lambda_{j}^{1} z_{f j}-q_{f}^{-}=z_{f o}+\alpha d_{f}^{z}, \quad \quad f=1, \ldots, h,(b) \\
& \sum_{j=1}^{n} \lambda_{j}^{2} z_{f j}+q_{f}^{+}=z_{f o}-\alpha d_{f}^{z}, \quad f=1, \ldots, h,(c) \\
& \sum_{j=1}^{n} \lambda_{j}^{2} v_{p j}+n_{p o}-t_{p o}=v_{p o}, \quad 1,(d) \\
& \sum_{j=1}^{n} \lambda_{j}^{2} y_{r j}-s_{r}^{+}=y_{r o}+\alpha d_{r}^{y}, \quad r=1(e) \\
& \sum_{j=1}^{n} \lambda_{j}^{2} y_{r_{1} j}-\bar{s}_{r_{1}}=y_{r_{1} o}+\alpha d_{r_{1}}^{y}, \quad \quad r_{1}=1, \ldots, s_{1},(f) \\
& \sum_{j=1}^{n} \lambda_{j}^{2} v_{1 j} \leq f\left(\sum_{j=1}^{n} \lambda_{j}^{2} y_{1 j}\right), \quad(g) \\
& n_{p o} . t_{p o}=0, \quad p=1,(h) \\
& n_{p o} \geq 0, t_{p o} \geq 0, \alpha \geq 0, \quad p=1,(i) \\
& \lambda_{j}^{1} \geq 0, \lambda_{j}^{2} \geq 0, \quad j=1, \ldots, n,(j) \\
& s_{i}^{-} \geq 0, s_{r}^{+} \geq 0, \quad i=1, \ldots, m, r=1,(k) \\
& q_{f}^{+} \geq 0, q_{f}^{-} \geq 0, \bar{s}_{r_{1}}^{-+} \geq 0, \quad f=1, \ldots, h, r_{1}=1, \ldots, s_{1},(l)
\end{aligned}
$$

For analysing the supplier (mine) in the supply chain, the presented model (3) is as follows: 
A Novel DEA Approach for Evaluating Sustainable Supply Chains with Undesirable Factors

$$
\begin{array}{ll}
\operatorname{Max} & \alpha+\varepsilon\left(\sum_{i=1}^{m} s_{i}^{-}+\sum_{f=1}^{h} q_{f}^{+}\right) \\
\text {s.t. } & \sum_{j=1}^{n} \lambda_{j}^{1} x_{i j}+s_{i}^{-}=x_{i o}-\alpha d_{i}^{x}, \quad i=1, \ldots, m,(a) \\
& \sum_{j=1}^{n} \lambda_{j}^{1} z_{f j}-q_{f}^{+}=z_{f o}+\alpha d_{i}^{z}, f=1, \ldots, h,(b) \\
& \alpha \geq 0, \lambda^{1} \geq 0, s^{-} \geq 0, q^{+} \geq 0,
\end{array}
$$

For analysing the manufacturer and dealing with the undesirable output of this stage, the presented model (4) is as follows:

$$
\begin{aligned}
& \max \quad \alpha+\varepsilon\left(\sum_{r=1}^{1} s_{r}^{+}+\sum_{r_{1}=1}^{s_{1}} \bar{s}_{r}^{+}+\sum_{p=1}^{1}\left(n_{p o}-t_{p o}\right)+\sum_{f=1}^{h} q_{f}^{-}\right) \\
& \text {s.t. } \quad \sum_{j=1}^{n} \lambda_{j}^{2} z_{f j}+q_{f}^{-}=z_{f o}-\alpha d_{f}^{z}, \quad f=1, \ldots, h,(c) \\
& \sum_{j=1}^{n} \lambda_{j}^{2} v_{p j}+n_{p o}-t_{p o}=v_{p o}, \quad \quad p=1,(d) \\
& \sum_{j=1}^{n} \lambda_{j}^{2} y_{r j}-s_{r}^{+}=y_{r o}+\alpha d_{r}^{y}, \quad r=1,(e) \\
& \sum_{j=1}^{n} \lambda_{j}^{2} y_{r_{1} j}-\bar{s}_{r_{1}}=y_{r_{1} o}+\alpha d_{r_{1}}^{y}, \quad \quad r_{1}=1, \ldots, s_{1},(f) \\
& \sum_{j=1}^{n} \lambda_{j}^{2} v_{1 j} \leq f\left(\sum_{j=1}^{n} \lambda_{j}^{2} y_{1 j}\right), \quad(g) \\
& n_{p o} . t_{p o}=0, \quad p=1,(h) \\
& n_{p o} \geq 0, t_{p o} \geq 0, \alpha \geq 0, \quad \quad p=,(i) \\
& \lambda_{j}^{2} \geq 0, \quad j=1, \ldots, n,(j) \\
& s_{r}^{+} \geq 0, \quad i=1, \ldots, m, r=1(k) \\
& q_{f}^{-} \geq 0, \bar{s}_{r_{1}}^{+} \geq 0, \quad f=1, \ldots, h, r_{1}=1, \ldots, s_{1},(l)
\end{aligned}
$$


As mentioned in model (2) $y_{1}$ is a desirable output and $v_{1}$ is an undesirable output which is a by-product of the desirable output.

Theorem 1. A solution of model (2) is Pareto optimal if and only if $n^{*}=0, t^{*}=0, \alpha^{*}=0$, and $S^{*}=0$ ( sum of slack variables $)$.

Proof: By contradiction suppose any of these variables are not equal to zero. For each case, it is possible to find a solution which dominates the optimal solution and as a result destroy the Pareto optimality condition and vice versa.

According to model (6) two scenarios can be analysed

In the first scenario the production of desirable outputs is in efficient status and are not being changed.

Theorem 2. In a case that no improvements are suggested for desirable outputs, i.e., $\alpha^{*}=0$ and $s^{-^{*}}=0, s^{+^{*}}=0$, then the undesirable outputs can be increased, decreased, or remains unchanged.

Proof. In the first case when undesirable outputs can make improvements it can be concluded that $n^{*}>0$. Thus, $y_{1 o}$ is changed into $v_{1 o}-n_{1}^{*}=\sum_{j=1}^{n} \lambda_{j}^{* 2} v_{1 j}$ and satisfies the equation $\sum_{j=1}^{n} \lambda_{j}^{* 2} v_{1 j} \leq f\left(\sum_{j=1}^{n} \lambda_{j}^{* 2} y_{1 j}\right)$ Which implies this is a feasible strategy for the decision maker according to model (2).

In the second case when undesirable outputs can make decrements it clearly results in that $n^{*}=0, t^{*}=0$. This case according to the model (2) is a feasible strategy.

According to the second scenario, it can be concluded that the necessary and sufficient condition for Pareto-optimality is $\alpha^{*}=0$ and $n^{*}=t^{*}=0$. increased.

In the second scenario, the production of desirable outputs can be

Theorem 3. Consider a case where the desirable outputs are improved, i.e., $\alpha^{*} \neq 0$ or $S^{*} \neq 0$ (sum of slacks and surpluses), then the undesirable outputs can be decreased, increased, or remains changed.

Proof. In the first strategy when undesirable outputs are decreased, which means $n^{*}>0, \quad t^{*}=0$, according to the optimal solution of model (2), one can write the equation $\sum_{j=1}^{n} \lambda_{j}^{* 2} v_{1 j}=v_{1 o}-n^{*}, v_{1 o}-n^{*} \leq f\left(\sum_{j=1}^{n} \lambda_{j}^{* 2} y_{1 j}\right)$.

In the second case, for which the undesirable outputs did not change, this is a possible strategy according to the optimal solution of model (3) where $t^{*}=0$ and $n^{*}=0$. In this case we have $\sum_{j=1}^{n} \lambda_{j}^{* 2} v_{1 j}=v_{1 o}, v_{1 o} \leq f\left(\sum_{j=1}^{n} \lambda_{j}^{* 2} y_{1 j}\right)$.

In the third strategy when undesirable outputs are increased, which means $n^{*}=0, t^{*}>0$ according to the optimal solution of model (2) it results 
A Novel DEA Approach for Evaluating Sustainable Supply Chains with Undesirable Factors

$\sum_{j=1}^{n} \lambda_{j}^{* 2} v_{1 j}=y_{1 o}+t^{*}$. But here there is no guarantee that the above equation holds true. That means $v_{1 o}+t^{*}$ satisfies the upper bound limit, i.e., $v_{1 o}+t^{*} \leq f\left(\sum_{j=1}^{n} \lambda_{j}^{* 2} y_{2 j}\right)$. Thus, the new amount of $v_{1 o}$, i.e., $v_{1 o}+t^{*}$, should be investigated to satisfy constraint(e).

\section{Case study}

This study aims to evaluate eleven cement companies in year 2017 for Iranian Stock Exchange Market as an application whilst considering the sociological, environmental, economic, and technological aspects. Consider a supply chain consisting of two stages, the mine and the manufacturer, in a cement factory. The inputs of mine are the costs of manpower, $\left(i_{l}\right)$ in Billion Rials, and costs of transportation, $\left(i_{2}\right)$ in Billion Rials. Output of mine is raw materials, $\left(z_{1}\right)$ in Ton. Considering the second stage, manufacturer, the input is raw materials, $z_{l}$, and the outputs are annual production, $\left(\mathrm{o}_{1}\right)$ in Ton, the amount of emission of $\mathrm{CO}_{2}\left(\mathrm{O}_{2}\right)$ in $\mathrm{Kg}$, and net profit $\left.\mathrm{O}_{3}\right)$ in Billion Rilas. Among these outputs, the amount of emission of $\mathrm{CO}_{2}$ is an undesirable output which is a by-product of annual production which is a desirable output. See figure 1. The pollutants are undesirable by-product and need to be minimized. But these undesirable outputs cannot be controlled only. Its variations are dependent on annual productions. If there is a desire to minimize the $\mathrm{CO}_{2}$ emission, the production of annual production inevitably will be minimized. Consider Figure 1.

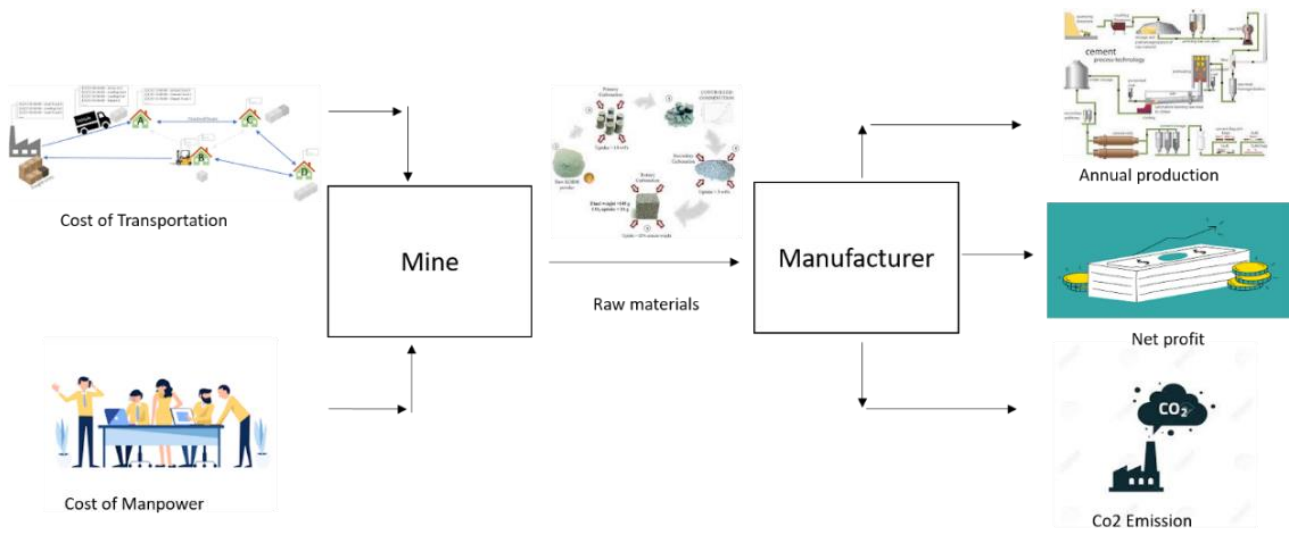

Figure 1. A two-stage supply chain

Consider the inputs, intermediates, and outputs of the two-stage supply chain as mentioned in Table 1. The inputs of the mine are the costs of manpower, and costs of transportation. The output of mine is raw materials. In relative to the second stage, the manufacturer, the input is raw materials and the outputs are

DOI: 10.24818/18423264/55.2.21.11 
the amount of emission of $\mathrm{CO}_{2}$, the annual production, and net profit. Among these outputs, the amount of emission of $\mathrm{CO}_{2}$ is an undesirable output which is a byproduct of annual production which is a desirable output. It needs to be noted that in this application, the function ' $f$ ' in constraint $(\mathrm{g})$ is considered is considered 0.2 times of the desirable output, more than that of the undesirable output.

Table 1. Dataset

\begin{tabular}{|l|c|c|c|c|c|c|}
\hline DMUs & $i_{1}$ & $i_{2}$ & $z_{1}$ & $o_{1}$ & $o_{2}$ & $o_{3}$ \\
\hline DMU1 & 452 & 597.373 & 6448816 & 5150000 & 7705653.9 & 225.040 \\
\hline DMU2 & 1113 & 862.900 & 11166888 & 9000000 & 10030000.0 & 512.160 \\
\hline DMU3 & 803 & 443.303 & 2064312 & 1300000 & 2537806.0 & 958.292 \\
\hline DMU4 & 233 & 201.074 & 2048094 & 1861000 & 2006340.6 & 124.160 \\
\hline DMU5 & 456 & 888.740 & 4858381 & 2500000 & 3716200.0 & 182.809 \\
\hline DMU6 & 570 & 861.937 & 9453153 & 5000000 & 12339549.0 & 436.897 \\
\hline DMU7 & 558 & 285.063 & 3561725 & 2656500 & 5182500.0 & 137.706 \\
\hline DMU8 & 177 & 387.807 & 3125730 & 2313949 & 4857119.0 & 140.029 \\
\hline DMU9 & 216 & 252.881 & 5559027 & 3000000 & 8419791.2 & 141.193 \\
\hline DMU10 & 483 & $8,332.634$ & $6,702,394$ & $5,700,000$ & $11,028,486.9$ & 293.258 \\
\hline DMU11 & 225 & $2,621.211$ & $3,140,708$ & $1,827,000$ & $5,234,623.6$ & 147.440 \\
\hline
\end{tabular}

In Table 2, 3, and 4 results of models (2), (3), and (4) for evaluating the whole chain, the mine, and the manufacturer.

Table 2. The results of Model (3) for the Mine

\begin{tabular}{|c|c|c|}
\hline DMUs & $\alpha^{*}$ & $S^{*}$ \\
\hline DMU1 & 201.42 & 304006801.2 \\
\hline DMU2 & 679.0 & 354884885.0 \\
\hline DMU3 & 722.7 & 349363804.3 \\
\hline DMU4 & 153.4 & 107899239.8 \\
\hline DMU5 & 267.2 & 667719038.2 \\
\hline DMU6 & 202.6 & 431902472.5 \\
\hline
\end{tabular}


A Novel DEA Approach for Evaluating Sustainable Supply Chains with Undesirable Factors

\begin{tabular}{|c|c|c|}
\hline DMU7 & 419.5 & 123020385.8 \\
\hline DMU8 & 55.5 & 245614908.5 \\
\hline DMU9 & 0.00 & 0.00000000 \\
\hline DMU10 & 222.5 & 528360121.8 \\
\hline DMU11 & 102.9 & 119245067.4 \\
\hline
\end{tabular}

Table 3. The results of models (2) and (4)

\begin{tabular}{|c|c|c|c|c|c|c|c|c|}
\hline \multirow{2}{*}{ DMUs } & \multicolumn{2}{|c}{ Results of } & \multicolumn{1}{c}{ Model (4) } & for the & manufacturer & \multicolumn{2}{c|}{ Results } & \multicolumn{2}{c|}{ Model (2) for the supply chain } \\
\cline { 2 - 9 } & $\alpha^{*}$ & $n^{*}$ & $t^{*}$ & $S^{*}$ & $\alpha^{*}$ & $n^{*}$ & $t^{*}$ & $S^{*}$ \\
\hline DMU1 & 772562.9 & 21451196 & 0 & 21869304 & 201.4 & 14413626 & 0 & 390503500 \\
\hline DMU2 & 1026019.4 & 958678.9 & 0 & 21382380 & 679 & 0 & 9085693.7 & 462062676 \\
\hline DMU3 & 182502.5 & 6943600.3 & 0 & 47751653 & 722.7 & 5162860.5 & 0 & 412325895 \\
\hline DMU4 & 0 & 0 & 0 & 0 & 0 & 0 & 0 & 107906526 \\
\hline DMU5 & 695524.7 & 0 & 3617903 & 123944380 & 267.2 & 0 & 10428740 & 849839133 \\
\hline DMU6 & 847785.5 & 39096146 & 0 & 320174815 & 202.6 & 30793109 & 0 & 822998833 \\
\hline DMU7 & 486941.7 & 21704007 & 0 & 34957151 & 419.5 & 16937970 & 0 & 198687309 \\
\hline DMU8 & 307924.3 & 20967584 & 0 & 45304590 & 55.5 & 17951660 & 0 & 316680434 \\
\hline DMU9 & 1219052 & 41682930 & 0 & 134815572 & 0 & 29740931 & 0 & 236819822 \\
\hline DMU10 & 424675.8 & 48787492 & 0 & 49235926 & 222.5 & 44629491 & 0 & 613112197 \\
\hline DMU11 & 267439.2 & 24199306 & 0 & 102311347 & 102.9 & 21580444 & 0 & 243925793 \\
\hline
\end{tabular}

Consider DMU4 for the first stage, there is possible optimal changes $\alpha^{*}$ (first phase) and a positive sum of optimal slacks $S^{*}$ (second phases). Thus, this DMU does not perform efficiently in the first stage. In the second stage, this unit does not have proportional changes but it has a positive optimal value in the second phase. In this stage $n^{*}=0$ and $t^{*}=0$ also reveal that no changes need to be executed. But, the sum of optimal slack variables is positive in this stage. It shows that this unit does not have efficient performance and it is not a non-dominated unit. Now consider the whole chain. Results of model (4) reveal that $D M U_{4}$ has an efficient status. All the optimal variables are equal to zero that means this unit is in efficient status. But, as we know, if we do not consider the inter-relations between the stages, concise and accurate information cannot be secured as to the system. In black box evaluation $\mathrm{DMU}_{4}$ has efficient status, but it does not 
perform efficiently in the first and second stages, $\alpha^{*}>0$ and $S^{*}>0 . D M U_{9}$ performs efficiently in the first and second stages. This means that there are no proportional and non-proportional changes in the first and second phases, $\alpha^{*}=0$, $S^{*}=0$. In second stage, of the manufacturer, does not need proportional changes, but it has a positive sum of optimal slacks in objective function of the second phase. This shows that it does not grasp the efficient performance. In this stage, the optimal value of the balancing variables, $n^{*}>0$ and $t^{*}=0$, shows that undesirable output can also be solely decreased. In evaluation the chain, it is clear that it does not performs efficiently and needs proportional and non-proportional changes, $\alpha^{*}>0, S^{*}>0$. It can be also concluded that desirable outputs can be increased since the amount of its dependent factor (undesirable output) is less than the defined quality level and it can be also increased directly.

Now, consider the first stage of $D M U_{5}$. In this stage it does not perform efficiently in both phases, proportional and non-proportional changes $\alpha^{*}>0$, $S^{*}>0$. In the second stage in relative to manufacturer, this unit need proportional changes, $\alpha^{*}>0$. In considering optimal values of the balancing variables, $n^{*}, p^{*}$, in the optimal solution reveals that the undesirable output can be increased as in the evaluation it is optimal to increase the desirable output. This is rational since the desirable and undesirable outputs are respectively 3716200.0 and 182.809. As the undesirable output is less that the desirable output and they satisfy constraint (b) in which undesirable output is less than 0.2 times of the desirable output, thus in the optimal solution the desirable output can be increased. In such occasions there is a possibility for an undesirable output, as they are dependent on each other, to be incremented. The analysis in the second phase model reveals that the sum of optimal slack variables is positive. This means that $D M U_{5}$ also requires nonproportional changes to reach the efficient performance. Now, consider the entire chain. The analysis shows that it needs both proportional and non-proportional changes to reach the efficient status. It is important that this unit is being allowed to increase its undesirable output, since its value is less than the amount it can have according to the quality controls. Thus, it is possible to increase the desirable output, which dependently increases the undesirable output as well. Consider Figure 2 in which performances of stages as well as the whole supply chain are compared. The key feature of this model is in the circumstances where the undesirable output is less than the quality level that was defined by decision makers or managers. From the viewpoint of quality management, when the undesirable outputs are less than the predefined levels, it is possible to increase the undesirable outputs, since it will increase the desirable output synchronously. As mentioned, this is a newly presented method and model. In recent researches, the provided models have not paid attention to this issue. 
A Novel DEA Approach for Evaluating Sustainable Supply Chains with Undesirable Factors

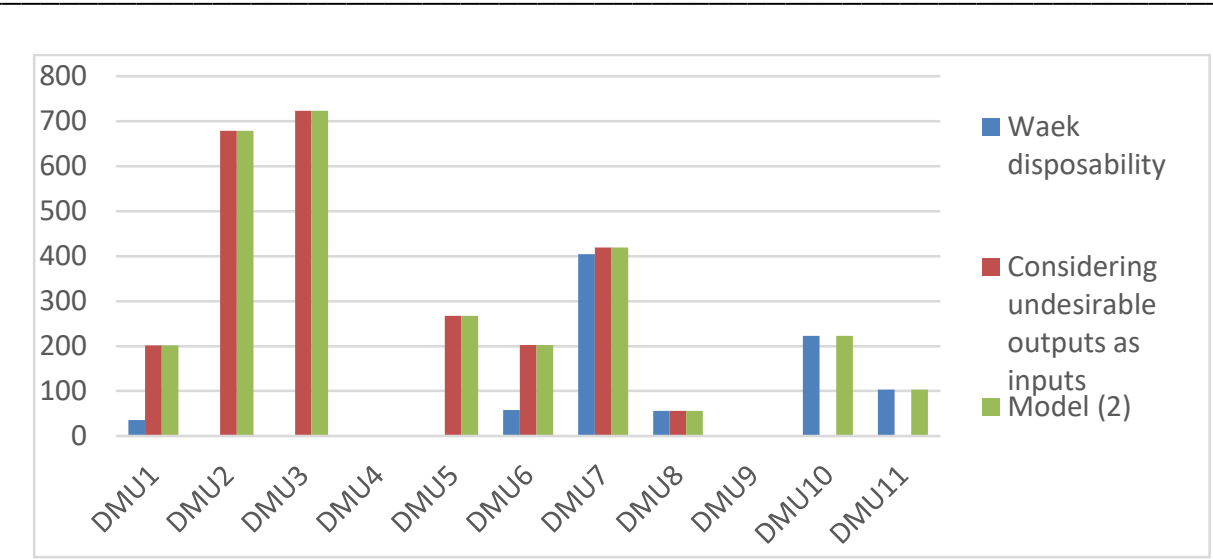

Figure 2. Comparison of performances

This way of dealing with dependent undesirable and desirable outputs can be considered in different DEA models for the assessment of performance of systems.

\section{Managerial implications}

Managers and decision maker in different systems desire to have more accurate information about the performance of their system for better making crucial decision for the future plans. For this purpose, here a comparison between the classic methods and the newly presented method will be provided. Consider the following Table 4 in which the results of analysis while two basic methods of dealing with undesirable outputs are considered, weak disposability for undesirable output and considering undesirable output as inputs. Model (2) is considered while in the first analysis the weak disposability of undesirable output is taken into consideration and the results are listed in Table 4. For the second comparison, the undesirable output is considered as input and model (2) is solved in such circumstances for which the results are also depicted in Table 4. Consider Figure 2.

Table 4. Comparison of model (6) with the classical methods

\begin{tabular}{|c|c|c|c|}
\hline DMUs & $\begin{array}{c}\text { Weak } \\
\text { disposability of } \\
\text { undesirable output }\end{array}$ & $\begin{array}{c}\text { Considering } \\
\text { undesirable } \\
\text { output as input }\end{array}$ & $\begin{array}{c}\text { Dependent } \\
\text { desirable and } \\
\text { undesirable } \\
\text { output }\end{array}$ \\
\hline DMU1 & 35.9 & 201.4 & 201.4 \\
\hline DMU2 & 0 & 679.0 & 679.0 \\
\hline DMU3 & 0 & 722.7 & 722.7 \\
\hline DMU4 & 0 & 0 & 0 \\
\hline DMU5 & 0 & 267.2 & 267.2 \\
\hline
\end{tabular}


Zohreh Moghaddas, Mohsen Vaez Ghasemi, Farhad Hosseinzadeh Lotfi

\begin{tabular}{|c|c|c|c|}
\hline DMU6 & 57.5 & 202.6 & 202.6 \\
\hline DMU7 & 403.9 & 419.5 & 419.5 \\
\hline DMU8 & 55.5 & 55.5 & 55.5 \\
\hline DMU9 & 0 & 0 & 0 \\
\hline DMU10 & 222.5 & 0 & 222.5 \\
\hline DMU11 & 102.9 & 0 & 102.9 \\
\hline
\end{tabular}

As it is clear the results are so different with each other the classification of efficient and inefficient DMUs are totally different. In these two analyses the relation between desirable and undesirable outputs are not consider. The important note in this comparison is that an efficient DMU under performance analysis of model (2) with weak disposability of undesirable output, considering it to be the input, and considering the dependency between the desirable and undesirable output are the same. While, those DMUs behave inefficiently may differ from each other. Except for DMU2, DMU4, and DMU5, other DMUs are tended to increase the preadmission of $\mathrm{CO}_{2}$. This matter can not be concluded from the second classic approach, considering the undesirable output as an input. While DMU2 and DMU5 are tended to decrease the emission of $\mathrm{CO}_{2}$ as it is possible for them to increase the amount of desirable output. This issue also can not be inferred from the classic methods. According to this information managers and decision makers are able to decide more accurately about the conditions of their systems and follow different strategies of increasing or decreasing the desirable output while have a sharp look at the situation of undesirable output which directly affect the performance.

\section{Conclusions}

In every production process the aim is to minimize consumption of inputs and maximize the production of desirable outputs. Outputs such as airborne particles, waste, and pollution are undesirable outputs that usually are by-products of desirable outputs. As the production of these kinds of undesirable outputs is inevitable, the best strategy for dealing with them is to consider the joint productions of desirable and undesirable outputs. DEA as a mathematical optimization technique, is being now widely used in performance evaluation of variety of different production systems. In almost every organization the process of generating the activity of undesirable outputs as well as the desirable ones are present. The presence of such outputs plays an important role, as environmental factors, in estimating the efficiency of DMUs. Thus, in this research efforts have been made to deal with the undesirable outputs from a new aspect, which is more in consistent with real world problems. Since most of the time, undesirable outputs are by-products of desirable ones. We consider this fact in DEA modelling and analyzed the presented models from different aspects. As environmental factors are important in sustainability of supply chains, we present this method in a supply

DOI: $10.24818 / 18423264 / 55.2 .21 .11$ 
A Novel DEA Approach for Evaluating Sustainable Supply Chains with Undesirable Factors

chain. Also, results of the case study show the dependency of production of desirable and undesirable outputs.

Considering the joint production of desirable and undesirable, many of the classic DEA models can be considered from this aspect.

\section{REFERENCES}

[1] Alemdar, T., Oren, M.N. (2006), Determinants of Technical Efficiency of Wheat Farming in Southeastern Anatolia, Turkey: A Nonparametric Technical Efficiency Analysis. Journal of Applied Sciences. 6(4), 827-830. DOI.10.3923/jas.2006.827.830;

[2] Bazaraa, M.S., Sherali, H.D., Shetty, C.M. (2006), Nonlinear Programming Theory and Algorithms. Published by John Wiley \& Sons, Inc., Hoboken, New Jersey. Published simultaneously in Canada, 3rd ed. ISBN: 978-0-471-48600-8; [3] Borgheipour, H., Hosseinzadeh, F.L., Moghaddas, Z. (2017), Implementing energy efficiency for target setting in the sugar industry of Iran. International Journal of Environmental Science and Technology, 14, 1697-1712. DOI.10.1007 /s13762-017-1285-3;

[4] Charnes, A., Cooper, W.W. and Rhodes, E. (1978), Measuring the Efficiency of Decision Making Units. European Journal of Operational Research, 2(6), 429-444. DOI. org/10.1016/0377-2217(78)90138-8;

[5] D'Inverno, G., Carosi, L., Romano, G., Guerrini, A. (2018), Water Pollution in Wastewater Treatment Plants: An Efficiency Analysis with Undesirable Output. European Journal of Operational Research. 269(1), 24-34.

DOI.10.1016/j.ejor.2017.08.028;

[6]Färe, R., Carl A. Pasurka, Jr.(1989), Multilateral Productivity Comparisons when some Outputs Are Undesirable: A Nonparametric Approach. The Review of Economics and Statistics. 71(1), 90-98. DOI.10.2307/1928055;

[7] Färe, R., Grosskopf, S. (2003), Nonparametric Productivity Analysis with Undesirable Outputs: Comment. American Journal of Agricultural Economics. 85(4), 1070 74. DOI.10.1111/1467-8276.00510;

[8] Golany, B., Roll, Y. (1989), An Application Procedure for DEA. Omega. 17(3), 237-250. DOI.org/10.1016/0305-0483(89)90029-7;

[9] Huang, T.H., Chung, M.T., (2017), Do Undesirables Matter on the Examination of Banking Efficiency Using Stochastic Directional Distance Functions. The Quarterly Review of Economics and Finance. 65, 194-211. DOI.10.1016/j.qref.2016.09.007;

[10] Hailu, A., Veeman, T. (2001), Non-Parametric Productivity Analysis with Undesirable Outputs: An Application to the Canadian Pulp and Paper Industry. American Journal of Agricultural Economics. 83(3), 605-616. DOI.org/10.1111/0002-9092.00181; [11] Iqbal, A., Seiford, L.M. (1990), Translation Invariance in Data Envelopment Analysis. Operations Research Letters. 9(6), 403-405. DOI.org/10.1016/0167-6377(90)90061-9; 
Zohreh Moghaddas, Mohsen Vaez Ghasemi, Farhad Hosseinzadeh Lotfi

[12] Kalantary, M., Farzipoor Saen, R. (2019), Assessing Sustainability of Supply Chains: An Inverse Network Dynamic DEA Model. Computers \& Industrial Engineering. 135, 1224-1238. DOI.org/10.1016/j.cie.2018.11.009;

[13] Kuosmanen, T. (2005), Weak Disposability in Nonparametric Productivity Analysis with Undesirable Outputs. American Journal of Agricultural Economics. 87(4), 1077-1082. DOI. 10.1111/j.1467-8276.2008.01238.x;

[14] Liu, X., Guo, P., Guo, S. (2019), Assessing the Eco-Efficiency of a Circular Economy System In China's Coal Mining Areas: Emergy and Data Envelopment Analysis. Journal of Cleaner Production. 206, 1101_1109. DOI:

10.1016/j.jclepro.2018.09.218;

[15] Rajesh, R. (2020), Sustainable Supply Chains in the Indian Context: An Integrative Decision-Making Model. Technology in Society. 61, 101230.

DOI.org/10.1016/j.techsoc.2020.101230;

[16] Pouralizadeh, M., Amirteimoori, A., Vaez Ghasemi, M. (2019), Supply

Chain Performance Evaluation in the Presence of Undesirable Products: A Case on Power Industry AIMS Energy, 8(1): 48-80, 2019;

[17] Scheel, H. (2001), Undesirable Outputs in Efficiency Valuations. European Journal of Operational Research. 132(2), 400-410. DOI.org/10.1016/S0377-

2217(00)00160-0;

[18] Seiford, L.M., Zhu, S. (2002), Modeling Undesirable Factors in Efficiency Evaluation. European Journal of Operational Research. 142(1), 16-20. DOI.org/10.1016/S0377-2217(01)00293-4;

[19] Shephard, R.W. (1974), Indirect Production Functions (Mathematical Systems in Economics). Hain Meisenheim am Glan. 99 pages. ISBN-10:

3445011125;

[20] Shirazi, F., Mohammadi, E. (2019), Evaluating Efficiency of Airlines: A

New Robust DEA Approach with Undesirable Output. Research in

Transportation Business \& Management. 33, 100467;

[21] Song, M., Peng, J., Wang, J., Dong, L. (2018), Better Resource

Management: An Improved Resource and Environmental Efficiency Evaluation Approach that Considers Undesirable Outputs. Resources, Conservation and Recycling. 128, 197-205. DOI.10.1016/j.resconrec.2016.08.015;

[22] Tyteca, D. (1997), Linear Programming Models for the Measurement of Environmental Performance of Firms Concepts and Empirical Results. Journal of Productivity Analysis. 8(2), 183-197. DOI.org/10.1023/A:1013296909029;

[23] Vaez-Ghasemi, Moghaddas, Z., Farzipoor Saen, R., (2021). Cost efficiency evaluation in sustainable supply chains with marginal surcharge values for harmful environmental factors: a case study in a food industry. Operational Research. Doi.org/10.1007/s12351-021-00641-6;

[24] Zhou, P., Ang, B.W., Poh, K.L. (2006), Slacks-based Efficiency Measures for Modeling Environmental Performance. Ecological Economics. 60(1), 111118. DOI.org/10.1016/j.ecolecon.2005.12.001. 